\title{
OBSERVASI SIKLUS ESTRUS \\ PADA ANOA (Bubalus depressicornis) \\ DI ANOA BREEDING CENTRE MANADO
}

\author{
Martino R. M. Lago ${ }^{1}$, E. Pudjihastuti ${ }^{1 *}$, R. H. Wungow ${ }^{1}$, \\ L. R. Ngangi ${ }^{1}$, J. Kinho ${ }^{2}$ \\ ${ }^{1}$ Fakultas Peternakan Universitas Sam Ratulangi Manado, 95115 \\ ${ }^{2}$ Balai Penelitian dan Pengembangan Lingkungan Hidup dan Kehutanan Manado, \\ 95259
}

\begin{abstract}
ABSTRAK
Anoa adalah satwa endemik Sulawesi dan merupakan satwa terbesar diantara populasi satwa daratan Sulawesi. Populasinya kian menurun dari waktu ke waktu, sehingga perlu dilakukan upaya konservasi berkelanjutan dengan manjemen reproduksi yang baik. Salah satu manajemen reproduksi yang diperhatikan adalah dengan mengetahui siklus reproduksi termasuk di dalamnya siklus estrus. Berdasarkan hal tersebut maka dilakukan penelitian observasi siklus estrus pada anoa di Anoa Breeding Centre Manado. Tujuan dari penelitian ini adalah untuk mengetahui siklus estrus pada anoa. Materi yang digunakan dalam penelitian adalah empat ekor anoa betina umur 2,5, 6,5, 7 dan 8 tahun. Pengambilan data dilakukan dengan cara focal animal sampling pada empat ekor anoa betina (Manis, Denok, Anna dan Rita). Deteksi estrus dilakukan dengan menggunakan metode deteksi estrus non otomatis. Pengamatan estrus dilakukan setiap hari, jam 06:00-18:00 WITA. Penentuan anoa estrus didasarkan pada tanda-tanda estrus (TTE) yang nampak dari luar dan kesedian anoa betina percobaan menerima jantan untuk kopulasi. Sedangkan pengukuran suhu rektal dilakukan setiap hari di pagi dan sore hari dengan memasukan thermometer ke dalam rektal anoa. Berdasarkan hasil observasi diperoleh TTE yang muncul selama estrus yaitu: gelisah, urinisasi, menggoyang-goyangkan ekor,
\end{abstract}

${ }^{1 *}$ Korespondensi (corresponding Author) Email: endangfapetunsrat@gmail.com vulva merah, bengkak dan basah serta mengeluarkan lendir transparan, mendekati dan mencium organ genital pejantan, menaiki, dinaiki dan diam dinaiki. Lama estrus yaitu satu hari dengan siklus estrus pada Manis 26 hari dan Denok 30 hari. Suhu rektal selama estrus yaitu $41,7^{0} \mathrm{C}$. Dari hasil penelitian dapat disimpulkan bahwa siklus estrus anoa yang berada di Anoa Breeding Centre Manadoberkisar antara 26-30 hari dengan lama estrus satu hari.

Kata kunci : anoa, siklus estrus, tandatanda estrus

\section{ABSTRACT}

OBSERVATION OF ANOA (Bubalus depressicornis) ESTRUS CYCLE IN ANOA BREEDING CENTRE OF MANADO . Anoa is endemic to the island of Sulawesi and the biggest wild animal among fauna in Sulawesi. This anoa population is decreasing, so that the population needs sustainable conservation involving good reproduction management. The strategy of the reproduction management was knowledge of this animal reproduction cycles including estrus cycles of anoa at the Anoa Breeding Centre Manado. Objective of this study was to evaluate estrus cycles of anoa. Materials used in this study were four heads of female anoa at ages of 2.5, 6,5, 7 and 8 years old. Data were collected by focal animal sampling on each female anoa (Manis, Denok, Anna and Rita). Estrus detection was applied using non- 
automatically estrus detection method. Estrus observation was conducted daily at 06.00-18.00 Indonesian central time. Estrus anoa was detected on the basis of the visual estrus symptom (VES) and readiness of female anoa receiving the female to copulate. Rectal temperature was measured daily in the morning and afternoon using thermometer. Results showed that based on observation of VES revealed the estrus symptom including nervous, urination, shaking tail, reddish vulva, swelling vulva and transparent mucus from vulva, coming near male anoa, smelling the male genital, attempting to mount another anoa, being mounted by anotherand stands to be mounted by one of her herdmates. Estrus time period was a day with estrus cycles of 26 days (Manis), 30 days (Denok). Average of rectal temperatures was $41.7^{\circ}$ C. It can be concluded that estrus cycles of anoa at Anoa Breeding Centre Manado was ranging from 26-30 days with estrus period was one day.

Key words: anoa, estrus cycles, estrus symptom.

\section{PENDAHULUAN}

Anoa adalah satwa endemik pulau Sulawesi dan merupakan satwa terbesar diantara populasi satwa daratan Sulawesi. Mereka hidup dan berkembangbiak di alam liar yakni di kawasan hutan yang belum sama sekali dijamah oleh manusia.Namun populasinya dari waktu ke waktu terus berkurang. Penyebab utama berkurangnya populasi anoa diduga karena perburuan liar, tingginya predator, kejadian penyakit, pengalihan fungsi hutan menjadi lahan pertanian, perindustrian dan pemukiman sehingga habitatnya berkurang dan terjadi fragmentasi (Burton et al., 2005).Dalam red list yang dikeluarkan oleh International Union for Concervation of Nature and Natural Recources (IUCN) Anoa diklasifikasikan sebagai endangered speciesatau satwa langka. Sedangkan, olehConvention of International Trade of Endangered Species of Wild Flora and Fauna (CITES) memasukkan Anoa ke dalam Appendix I yang artinya bebas dari segala bentuk perdagangan.

Populasi anoa terus mengalami penurunan dari waktu ke waktudanpopulasinya pada tahun 2002 diperkirakan berjumlah 3000-5000 ekor dan cenderung mengalami penurunan (IUCN, 2007).Habitat dan populasi anoa di hutan Sulawesi telah rusak yang disebabkan oleh penebangan liar dan perburuan serta adanya kegiatan merusak seperti peralihan fungsi hutan menjadi lahan pertanian dan pemukiman warga (Mustari, 2003). Dalam rangka meningkatkan populasi anoa maka perlu dilakukan manajemen reproduksi.

Salah satu manajemen reproduksi yang diperhatikan adalah dengan mengetahui siklus reproduksi termasuk di dalamnya siklus estrus. Disisi lain upaya pengembangbiakan di penangkaran tidak berjalan semestinya karena sifat soliter, liar, agresif dan perilakunya yang sulit diramalkan, cenderung monogami (Yudi, 
2011). Beberapa penelitian telah dilakukan pada bidang reproduksi. Namun, demikian informasi mengenai siklus dan tingkah laku estrus masih perlu dilakukan untuk mendapatkan informasi yang lebih pasti,karena masih terdapat berbagai macam perbedaan pendapat mengenai siklus estrus.

\section{MATERI DAN METODE PENELITIAN}

Penelitian dilaksanakan di Animal Breeding Centre milik dari Balai Penelitian dan Pengembangan Lingkungan Hidup dan Kehutanan (BP2LHK) Manado yang bekerjasama dengan Balai Konservasi Sumber Daya Alam (BKDSA) Sulawesi Utara. Penelitian ini berlangsung selama dua bulan mulai dari bulan MaretMei 2016. Pengambilan data dilakukan setiap hari dimulai pada pukul 06:00 18:00 WITA.

Anoa yang digunakan dalam penelitian ini adalah empat ekor anoa betina Denok (8 tahun), Anna (7 tahun)Manis (6,5 tahun)dan Rita (2,5 tahun). Anoa dikandangkan secara individual dalam kandang dengan ukuran $80 \mathrm{~m}^{2}$. Pemberian pakan dilakukan dua kali sehari yaitu pada pagi dan sore hari, dengan mengkombinasikan hijauan dan legum. Adapun alat yang digunakan selama penelitian berlangsung adalah thermometer, kamera, handicam dan alat tulis menulis.

$$
\text { Pengambilan data dilakukan }
$$
dengan metode observasi teknikfocal animal sampling pada tiga anoa betina (Denok, Ana, Manis, Rita). Deteksi estrus dilakukan dengan menggunakan metode deteksi estrus non otomatis yaitu melihat perubahan alat reproduksi dan dengan menggunakan pejantan pengusik.Pengamatan estrus dilakukan setiap hari sore jam 06:00-18:00 WITA. Penentuan anoa estrus didasarkan pada tanda-tanda estrus (TTE) yang nampak dari luar dan kesedian anoa betina percobaan menerima jantan untuk kopulasi. Sedangkan pengukuran suhu rektal dilakukan setiap hari di pagi dan sore hari dengan memasukan thermometer ke dalam rektal anoa. Namun, tidak dilakukan pengukuran suhu rektal pada Ana dan Denok, hal tersebut dikarenakan Ana bunting dan Denok sulit dikendalikan atau sifat liarnya yang masih ada.

Data diolah secara deskriptif dan disajikan dalam bentuk tabel dan grafik serta menunjukkan beberapa gambar.Variabel penelitian adalah:Tandatanda estrus (TTE), lama estrus, siklus estrus dan suhu rektal.

\section{HASIL DAN PEMBAHASAN}

\section{Tanda-tanda Estrus}


Gejala klinis yang nampak dan terinvetarisir pada saat anoa estrus adalah menggoyang-goyangkan ekor (ekor diangkat), urinisasi saat melihat pejantan, gelisah (nervous) atau begerak berpindahpindah (agresif), mendekati pejantan, mencium organ genital pejantan (Gambar 1). Bismark dan Gunawan (1996) menyatakan bahwa anoa yang sedang estrus akan cenderung besifat agresif.

Ciri-ciri lain yang teramati pada saat anoa estrus yaitu menaiki sesama betina atau pejantan (Gambar 2), tidak menolak pejantan saat didekati dan berada dalam posisi siap kawin, TTE ini terjadi apabila anoa jantan digabungkan dengan anoa betina. Selanjutnya akan terjadi perubahan vulva menjadi bengkak dan lebih besar pada anoa yang sedang estrus dibandingkan dengan anoa yang non estrus (Gambar 3a), vulva agak kemerah-merahan sebagai akibat peningkatan sirkulasi atau aliran darah yang membesarkan pembuluhpembuluh darah didaerah vulva dan vulva terlihat basah oleh bekas sisa-sisa lendir (Gambar 3b). Feradis (2010) menyatakan bahwa selama estrus akan terjadi perubahan vulva. Perubahan vulva tersebut terjadi pada saat estrus dari keadaan mengkerut (keriput) menjadi bengkak. Beberapa gejala atau TTE yang teramati sesuai dengan pendapat dari Hafez (2002). Perubahan tingkah laku anoa yang dimanifestasikan dengan TTE yang nampak ini dapat digunakan sebagai patokan awal datangnya estrus.

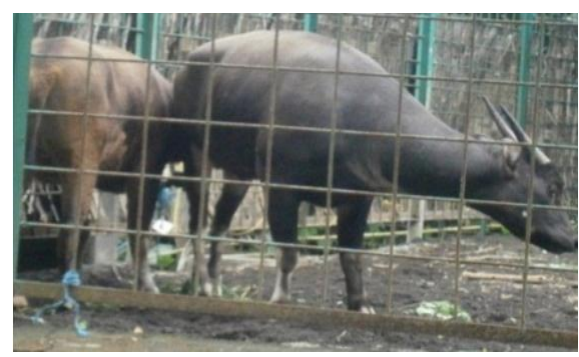

Gambar 1. Anoa betina yang sedang mencium organ genital jantan

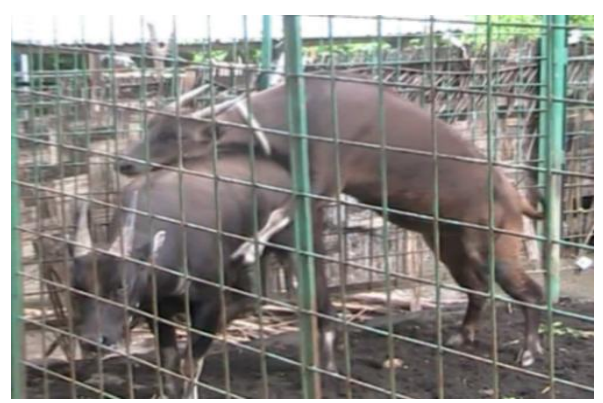

Gambar 2. Anoa betina estrus menaiki jantan 


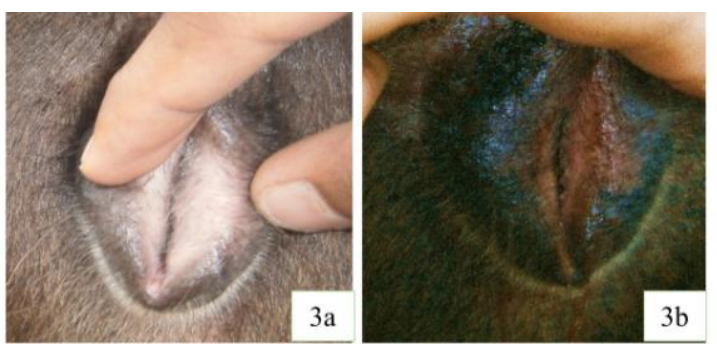

Gambar 3a. Vulva dari anoa yang non estrus

Gambar 3b Vulva anoa sedang estrus

Penggabungan antara anoa jantan dengan betina Denok dilakukan untuk meningkatkan derajat dari gejala estrus. Berdasarkan penelitian yang dilakukan oleh Signoret (1979) pada ternak babi, kontak visual saat penggabungan pejantan dan betina memberikan rangsangan berlanjut sampai dua hari setelah puncak estrus. Hal ini dibuktikan dengan munculnya hampir semua TTE (Tabel 1). Hal ini menggambarkan bahwa derajat gejala estrus pada anoa Denok lebih tinggi dibandingkan dengan anoa Rita dan Manis.Hal ini dapat dijelaskan karena adanya peranan saraf-saraf mata, pencium, pendengar pada betina sangat besar. Pheromone yang dihasilkan oleh pejantan maupun betina yang dikeluarkan melalui urine, feses, kelenjar keringat selanjutnya melalui udara dapat diterima oleh saraf pencium hewan betina, mengakibatkan adanya respon perilaku estrus pada anoa betina (Denok) melalui mekanisme hormonal. Hewan jantan dapat mendeteksi pheromone karena terdapat organ vomeronosal yang tedapat pada bagian dasar hidungnya.

Tabel 1. Pemunculan TTE pada anoa di Anoa Breeding Centre

\begin{tabular}{lllll}
\hline No & $\begin{array}{l}\text { Tanda-tanda Estrus yang } \\
\text { muncul }\end{array}$ & \multicolumn{2}{l}{ Nama Anoa } & \\
& Denok & Manis & Rita \\
\hline & Gelisah & $\sqrt{ }$ & - \\
2 & Urinisasi & $\sqrt{ }$ & $\sqrt{ }$ & - \\
3 & Menggoyang-goyangkan & $\sqrt{ }$ & $\sqrt{ }$ & - \\
& ekor & & & \\
4 & VMBB & $\sqrt{ }$ & $\sqrt{ }$ & - \\
5 & Lendir transparan & - & $\sqrt{ }$ & - \\
6 & Mendekati pejantan & $\sqrt{ }$ & $\sqrt{ }$ & - \\
7 & Mencium organ genital & $\sqrt{ }$ & $\sqrt{ }$ & - \\
& pejantan & & & \\
9 & Menaiki & $\sqrt{ }$ & - & $\sqrt{ }$ \\
10 & Dinaiki & $\sqrt{ }$ & $\sqrt{ }$ & - \\
\hline
\end{tabular}

Ket: VMBB = Vulva merah, bengkak dan basah, DD = Diam Dinaiki 
Walaupun dalam hasil pengamatan dilapang dijumpai anoa Denok tidak menampakkan gejala mengeluarkan lendir transparan, namun hal ini tidak mengurangi keakuratan penentuan fase estrus karena menurut Hurnik dan King (1987) pengeluaran lendir seviks hanya indikator minoritas pada tingkah laku estrus karena biasanya tidak konsisten pada setiap siklus estrus.

Anoa Rita tidak menampakkan sebagian besar TTE, data menunjukkan hanya gejala mengoyang-goyang ekor dan dinaiki yang muncul dan belum merupakan gejala atau TTE sehingga anoa Rita tidak terdeteksi estrusnya atau tidak berada dalam fase estrus selama penelitian berlangsung. Hal ini terjadi karena diduga anoa Rita belum mencapai usia dewasa kelamin atau pubertas. Di penangkaran dewasa kelamin pada anoa dicapai pada usia dua hingga tiga tahun (Yudi,. et al 2010; Jahja, 1987).

Perubahan tingkah laku anoa diam dinaiki (DD) adalah merupakan TTE yang menjadi patokan paling akurat dan menjadi indikator mayoritas untuk menyatakan bahwa anoa berada dalam fase estrus. (Gambar 4a, b).

Perilaku seksual anoa yang lain yang ditemui dilapang pada saat dikandangkan berpasangan yaitu jantan dan betina berendam bersama (Gambar 5a), jantan menciumi-menjilati daerah perineal betina (Gambar 5b), percumbuan jantan betina neck-to-neck (Gambar 6a) serta saling menanduk seakan-akan terjadi adu fisik (Gambar 6b).

Menanduk adalah salah satu cara anoa bertahan hidup di alam liar khususnya saat ada bahaya yang mengganggu keamanan mereka, bahkan antar anoa sendiri akan saling menanduk bila bertemu, hingga terjadi luka-luka dan tidak jarang ada yang hingga mati. Di saat estrus mereka akan saling menanduk, namun bedanya bukan sebagai bentuk pertahanan (survive) dengan berusaha melukai tapi hanya sebagai bentuk percumbuan yang dilakukan dengan lemah-lembut

(Gambar 6b).
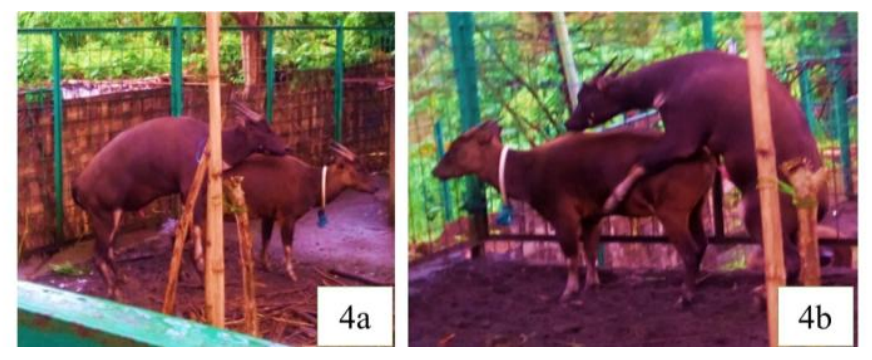

Gambar 4a dan Gambar 4b. Betina diam saat dinaiki pejantan 

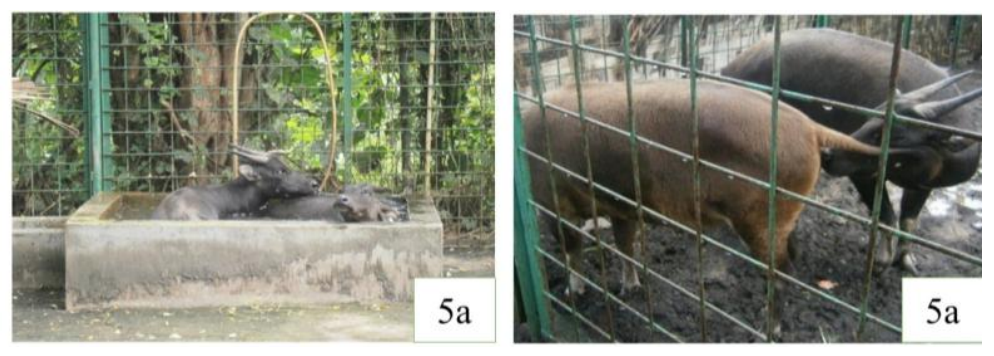

Gambar 5a. Anoa betina dan pejantan berendam bersama Gambar 5b. Pejantan menciumi-menjilati daerah perineal betin
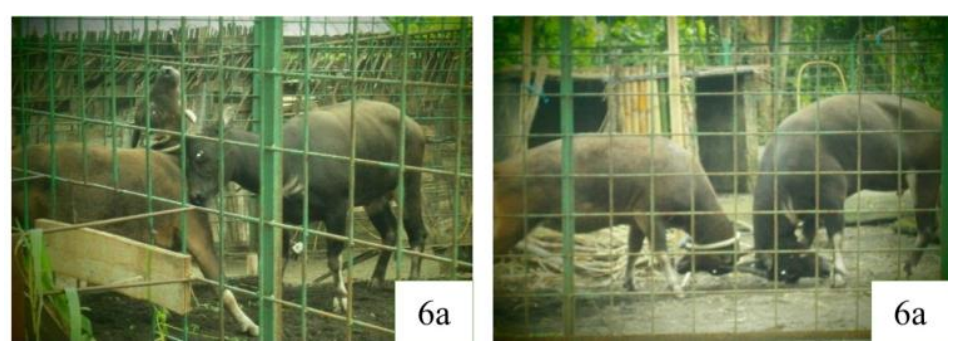

Gambar 6a. Percumbuan neck-to-neck

Gambar 6b. Saling menanduk saat bercumbu

Dalam penelitian ini juga dapat gejala yang nampak terlebih dahulu dinformasikan bahwa dari TTE yang kemudian diikuti oleh TTE yang lain terinventarisir, gejala gelisah atau (Tabel 2).

berpindah-pindah tempat merupakan

Tabel 2. Urut-urutan TTE yang muncul pada anoa betina estrus

\begin{tabular}{|c|c|}
\hline No & TTE yang muncul \\
\hline 1 & Gelisah \\
\hline 2 & Urinisasi \\
\hline 3 & Menggoyang-goyangkan ekor \\
\hline 4 & Vulva merah, bengkak dan basah \\
\hline 5 & Lendir transparan \\
\hline 6 & Mendekati pejantan \\
\hline 7 & Mencium organ genital pejantan \\
\hline 8 & Menaiki \\
\hline 9 & Dinaiki \\
\hline 10 & Diam dinaiki \\
\hline
\end{tabular}




\section{Siklus dan Periode Siklus}

Siklus estrus anoa bervariasi antara individu, yaitu berkisar 26-30 hari dengan nilai rataan 28 hari (hanya dari dua ekor anoa yang diamati). Penentuan siklus estrus ini didasarkan pada saat terjadinya perubahan tingkah laku DD, berhenti, sampai tingkah laku tersebut muncul kembali.

Hasil pengamatan ini berbeda dengan hasil yang diperoleh oleh Yusuf,. et al (2008), yang melakukan induksi estrus anoa menggunakan kombinasi PMSG dan PGF2alfa dengan hasil siklus estrus anoa 21 hari. Hal ini dapat saja terjadi, karena siklus estrus dapat berbeda diantara betina lainnya (Hafez, 2002). Siklus estrus betina dipengaruhi oleh banyak faktor seperti menyusui, produksi susu, kondisi tubuh dan nutrisi. Feradis (2010) menyatakan bahwa siklus estrus yang terjadi pada ternak adalah karena pengaturan hormonal yang dihasilkan secara internal dan pengaturan proses hormonal tersebut berbeda-beda untuk tiap jenis dan bangsa ternak itu sendiri.

Lama estrus dapat dinyatakan sebagai saat anoa betina tetap siap sedia dinaiki oleh pejantan atau teaser. Lama periode estrus anoa yang diperoleh dalam penelitian ini berkisar satu hari (Tabel 3).Lama estrus lebih banyak dipengaruhi oleh faktor bangsa, musim, umur, suhu, pakan, dan respon individual ternak, lebih lanjut dikatakan oleh Frandson (1992) dan Feradis (2010) bahwa sama halnya dengan siklus estrus, maka lama estrus juga bervariasi untuk setiap spesies maupun individu.Frandson (1992) waktu Perhitungan lama estrus bertujuan untuk memprediksi waktu terjadinya ovulasi, lama kapasitasi sperma didalam saluran kelamin betina, lama kemampuan bertahan sel telur setelah diovulasikan.

Tabel 3. Lama Siklus dan Periode Estrus pada Anoa di Anoa Breeding Centre

\begin{tabular}{llllll}
\hline No & Nama Anoa & $\begin{array}{l}\text { Umur } \\
\text { (Tahun) }\end{array}$ & $\begin{array}{l}\text { Frekuensi } \\
\text { Beranak } \\
(\text { Kali) }\end{array}$ & $\begin{array}{l}\text { Lama } \\
\text { Estrus } \\
\text { (Hari) }\end{array}$ & $\begin{array}{l}\text { Lama } \\
\text { Siklus } \\
\text { Estrus } \\
\text { (Hari) }\end{array}$ \\
\hline 1 & Denok & 6 & $\left.2^{*}\right)$ & 1 & 30 \\
2 & Manis & 7 & $\left.2^{*}\right)$ & 1 & 26 \\
3 & Rita & 2,5 & - & - & - \\
4 & Anna & 8 & $\left.3^{*}\right)$ & - & - \\
\hline Rataan & & 5,87 & & 1 & 28
\end{tabular}

Ket: ${ }^{*}$ Dugaan sementara 


\section{Suhu Rektal}

Pengukuran suhu rektal dilakukan setiap hari dengan menggunakan thermometer yang dimasukkan kedalam rectum pada kedalaman tertentu dan menempel didinding mukosa dari rectum (Gambar 7). Kegiatan pengukuran suhu rektal dilakukan untuk menunjang penentuan waktu estrus dari anoa, lebih tepatnya sebagai salah satu langkah yang ditempuh untuk menunjang pendeteksian estrus pada hewan ternak.

Data ini menunjukkan terjadi peningkatan suhu rektal anoa Manis pada tanggal 15 Maret yaitu $41,8^{0} \mathrm{C}$ (Gambar 8) dan 16 April 2016 yaitu $41,7^{\circ} \mathrm{C}$ (Gambar 9) dari kisaran angka $37-39^{\circ} \mathrm{C}$, sedangkan untuk anoa Rita diperoleh kisaran suhu rectal terendah 37,4 dan tertinggi $38,8^{\circ} \mathrm{C}$ selama periode penelitian (Gambar 10 dan 11).Suhu rektal pada Rita selama penelitian masih dalam kisaran suhu normal, karena suhu tubuh (suhu rektal) normal berada pada kisaran 37,8-39,2 0C dengan rataan suhu rektal sebesar 38,5 0C (Kelly, 1984). Selanjutnya, Ismail (2006) mengatakan bahwapada kondisi tertentu suhu rectal dapat bervariasi, diantaranya saat estrus.

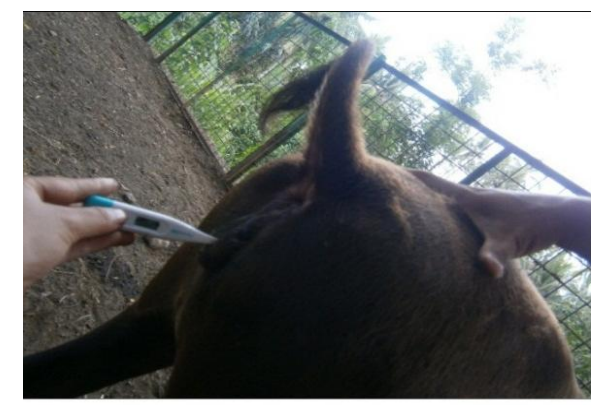

Gambar7. Pengukuran suhu rektal anoa

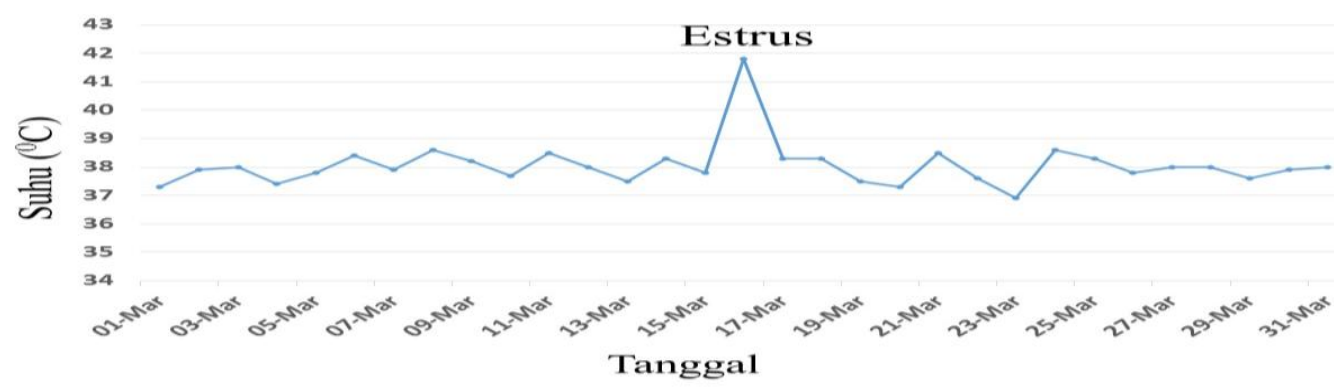

Gambar 8. Suhu rektal Manis pada bulan Maret yang menunjukan kenaikan secara drastis pada tanggal 15 Maret saat estrus. 


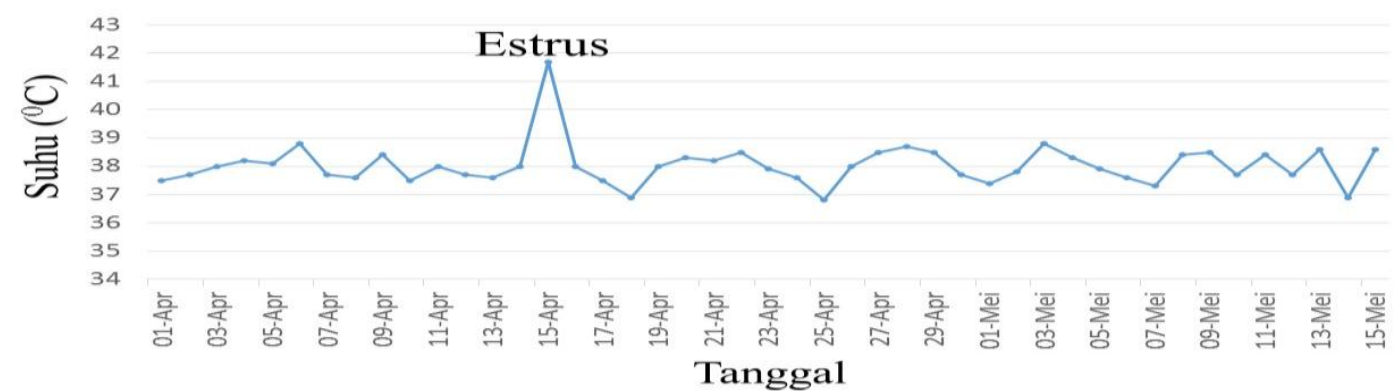

Gambar 9. Suhu rektal Manis pada bulan April-Mei yang menunjukan kenaikan secaradrastis pada tanggal 16 April saat estrus.

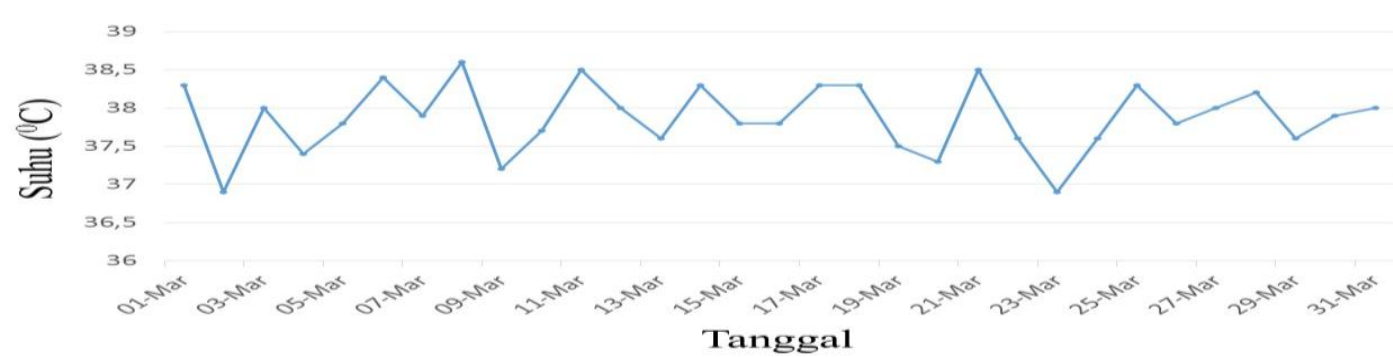

Gambar 10. Suhu rektal pada Rita di bulan Maret yang menunjukan tidak ada perubahan yang yang signifikan atau konstan berada pada suhu normal.

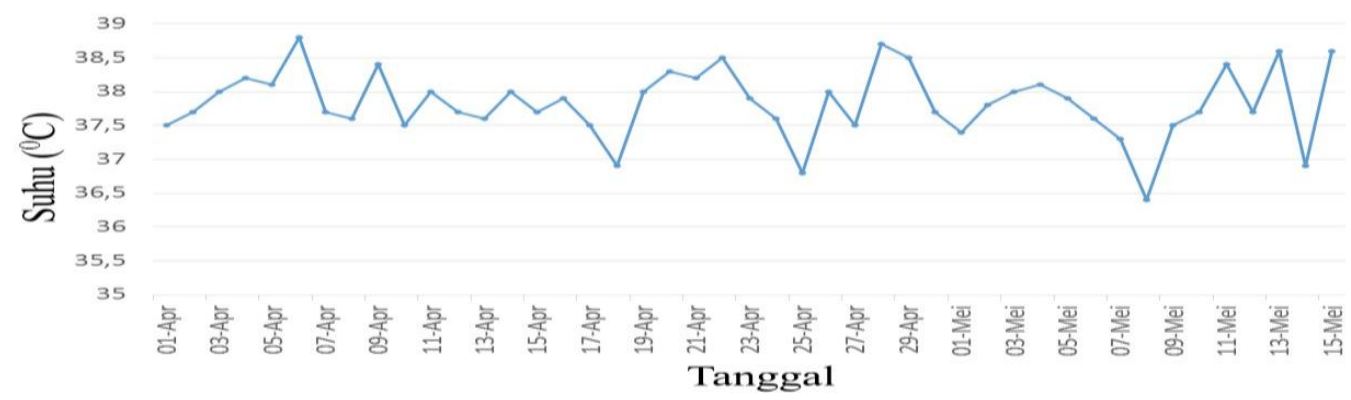

Gambar 11. Suhu rektal pada Rita di bulan April-Mei yang menunjukan tidak ada perubahan yang yang signifikan atau konstan berada pada suhu normal.

\section{KESIMPULAN}

Berdasarkan hasil observasi dilapangan maka dapat disimpulkan:

1. Siklus estrus anoa yang berada di Anoa Breeding Centre berkisar antara 26-30 hari dengan lama estrus satu hari.
2. Tanda-tanda estrus yang terinventarisasi selama penelitian antara lain: gelisah, urinisasi, menggoyang-goyangkan ekor, vulva (merah, bengkak dan basah), lendir transparan, mendekati pejantan, mencium organ genital pejantan, menaiki, dinaiki dan diam dinaiki. 


\section{DAFTAR PUSTAKA}

Bismark, M dan Gunawan, H. 1996. Pola Habitat dan Struktur Sosial Anoa Dataran Rendah di Taman Nasional Rawa Aopa Watumohai Sulawesi Tengah. Jur. Penelitian Kehutanan Vol. 10 (1): 6-16.

Burton, J., A. H. Mustari, \& A. A. MacDonald. 2005. Status dan rekomendasi: konservasi in situ Anoa (Bubalus sp.) dan implikasinya terhadap konservasi ex situ. Bul. Konservasi Alam 5: 35-39.

Feradis, MP. 2010. Bioteknologi Reproduksi Pada Ternak. Alfabeta, Bandung.

Frandson, R.D., 1992. Anatomi dan Fisiologi Ternak. Gajah Mada University- Press. Yogyakarta.

Hafez, ESE. 2002. Reproduction in Farm Animals. 6th Ed. Lea \& Febiger. Philadelphia.

Hurnik, JF dan King, GJ. 1987. Estrous behavior in confined beef cows. Jur. Animal Science 65 : 431-438

Ismail, M. 2006. Pengaruh Penyiramaman dan Penganginan tehadap Respons Termoregulasi dan Tingkah aku konsumsi Pakan Sapi Fries Holland Dara. Skripsi Program Studi Teknologi Produksi Ternak, Fakultas Peternakan, Institut Pertanian Bogor, Bogor.

IUCN (International Union for
Conservation and Natural
Resources). 2007. The IUCN Red
List of Threatened Species: 2001
Categories $\quad \&$

http://www.iucnredlist.org/. [3 April 2016].

Jahja, MM. 1987. The possibility of breeding anoa in captivity: an alternative for conservation of the species. BIOTROP, Special Publication, Vol.30 :101-108.

Kelly, W.R. (1984): Veterinary Clinical Diagnosis. 3rd ed. Baillere, Tindall, London.

Mustari AH. 2003. Ecology and Corservation of Lowland Anoa (Bubalus depressicornis) in Sulawesi, Indonesia. Thesis. University of George-August, Germany.

Signoret, JP. 1979. Reproductive Bahaviour of Pig. University of Florida. J. Repro. Fert. 11: 105-117.

Yudi, Yusuf TL, Purwantara B, Sajuthi D, Agil M, Managsang J, Hastuti YT, Wresdiyati T, Aditya dan Sudarwati. 2010. Morfologi dan Biometri Spermatozoa Anoa (Bubalus Sp.) yang diwarnai dengan Pewarna William's dan Eosin-Nigrosin. Jp Peternakan Vol. 33 (2) : 88-94

Yudi, Yusuf, TL, Purwantara, B, Sajuthi, D, Agil, M. 2011. Karakteristik Plasma Semen dan Kriopreservasi Semen Anoa (Bubalus sp.) yang dikoleksi Menggunakan Elektroejakulator. JITV Vol. 16 (1) : Hal 41-48.

Yusuf, TL, Purwanta, B, Sajuthi, D, Yudi. 2008. Pengembangbiakan Anoa Melalui Pengkajian dan Penerapan Teknologi Inseminasi Buatan (IB) dan Induksi Estrus sebagai Usaha Konservasi Satwa Langka. IPB. Bogor. 